\title{
Knowledge, Attitude and Practice on Hypertension Among Antihypertensive Medication Users
}

\author{
Shakti Shrestha, ${ }^{1}$ Bhoiraj Adhikari, ${ }^{2}$ Ramesh Sharma Poudel, ${ }^{3}$ Kailash Thapaliya, ${ }^{1}$ Tikaram Kharal, ${ }^{1}$ Mahanath \\ Bastakoti, ${ }^{1}$ Nanda Kishor Bhatta' \\ 'Department of Pharmacy, Shree Medical and Technical College, Bharatpur, Chitwan, Nepal, '2Department of Medicine, \\ Bharatpur District Hospital, Bharatpur, Chitwan, Nepal, ${ }^{3}$ Department of Hospital Pharmacy, Chitwan Medical College \\ Teaching Hospital, Bharatpur, Nepal.
}

\section{ABSTRACT}

Introduction: Hypertension is growing among the population of Nepal. We aimed to determine the current knowledge, attitude and practice of hypertension among hypertensive patients taking antihypertensive medication in the community of Central Nepal.

Methods: A cross-sectional study was conducted among the hypertensive patients in Bharatpur, Chitwan, Nepal from July 2015 to September 2015 using clustered sampling technique. Suitably designed and validated questionnaire of knowledge, attitude and practice on hypertension consisting of 27 questions were used to determine the KAP scores. The difference in the median KAP scores between sex, level of education and duration of hypertension were assessed using Mann-Whitney U test.

Results: A total of 200 patients met the inclusion criteria and majority of them were male $(60 \%)$, had received primary education $(36 \%)$ and had hypertension for $\geq 5$ years $(46.5 \%)$. The blood pressure ranged from 100-180/60-110 mmHg. The median K, A and P scores were 8 (6), 5 (1) and 6 (3) respectively. $\mathrm{K}$ and $\mathrm{A}$ were statistically associated with sex both at $\mathrm{p}<0.001$ and level of education (K at $\mathrm{p}<0.001$ and $A$ at $p=0.016$ ).

Conclusions: The current knowledge, attitude and practice among hypertensive patients using antihypertensive medication can be improved.

Keywords: attitude; hypertension; knowledge; practice.

\section{INTRODUCTION}

Hypertension globally contributes to nearly 7.5 million annual deaths ${ }^{1}$ and affecting a huge population, mostly in low- and middle-income countries, with its consequences such as heart disease, stroke, peripheral vascular diseases, kidney failure, and premature disability. ${ }^{2,3}$ The prevalence of hypertension in Nepal, including those under medication is $25.7 \% .{ }^{4}$ Hypertension can be management by pharmacological approaches and non-pharmacological approaches. ${ }^{5,6,7}$ Studies have demonstrated that good knowledge on hypertension is associated with better control of hypertension. ${ }^{8,9}$ However, community based studies have shown inadequate knowledge and, poor attitude and practice among patients with hypertension in Western Nepal ${ }^{8}$, Pakistan ${ }^{9,10}$ and USA. ${ }^{11}$ Such level of knowledge, attitude and practice affect the control of high blood pressure

Correspondence: Shakti Shrestha, Department of Pharmacy, Shree Medical and Technical College, Bharatpur, Chitwan, Nepal. Email: shaktishrestha@yahoo.com, Phone: +977-9855051899. 
despite of appropriate treatment. ${ }^{9}$ Furthermore, a study in per-urban area of Nepal with cardiovascular diseases (CVD) suggests that the community awareness of such diseases is poor. ${ }^{12}$ Therefore, we aimed to assess the baseline knowledge, attitude and practice of hypertension among hypertensive patients taking antihypertensive medication from Central Nepal. This baseline assessment will allow opportunities to develop interventional strategies that can create community awareness about hypertension.

\section{METHODS}

Study design and site: A community based descriptive study on knowledge, attitude and practice of hypertensive patients under antihypertensive medication was carried out in Bharatpur Sub-metropolitian city, Nepal from July 2015 to September 2015. The approval for this research was obtained from the Committee of Pharmaceutical Research (Shree Medical and Technical College), Bharatpur, Nepal and a written consent was taken from each patient before participating them for the study.

Inclusion and exclusion criteria: Participants who have been taking antihypertensive medication for more than 6 months due to diagnosis of hypertension, with or without concurrent disease, aged $>30$ years, both sex and willing to participate in the study were included in the study. Pregnant women and unresponsive participants were excluded.

Sample size and sampling: A sample size of 200 was taken to determine the pre-existing knowledge, attitude and practice (KAP) of the patients with hypertension taking antihypertensive medication using cluster sampling method. The 29 wards of Bharatpur submetropolitan city were considered as clusters. Since the sampling frame was unknown the recent population census of 2010 (199867) provided by the Bharatpur Municipality ${ }^{13}$ was used to determine required sample from each ward.

Data collection: The data on pre-existing KAP of 200 patients were collected using 27-itemed prevalidated $^{8,14,15}$ questionnaire through an interview method and blood pressure (BP) was measured using sphygmomanometer and stethoscope. A standard patient profile form was built for collecting data on sociodemographic information. There were 13 questions for assessing knowledge, 5 questions for assessing attitude and 9 questions for assessing practice. The English form of the questionnaire was translated into Nepali and pilot tested on 10 hypertensive patients ( 5 males and 5 females) who met our inclusion and exclusion criteria and the reliability using Cronbach's alpha test was $\square=0.708$. Patients involved in pilot were not included in the main study.

Data measurements: Knowledge and attitude answers were scored one for correct and zero for incorrect whereas, the practice answer was scored two for frequent adherence towards the guidelines, one for occasional adherence and zero for non-adherence (never) for all the questions except question 4, 7 and 8 in which never was scored two, occasional was score one and frequent was scored zero. The total score for each outcome variable was obtained by adding the score obtained from each question.

Statistical analysis and software used: The descriptive statistics were performed with IBM-SPSS version 20 (IBM Corporation, Armonk, NY, USA).

\section{RESULTS}

There were total of 200 hypertensive patients including 120 (60.0\%) males and 80 (40.0\%) females. Age ranged from 30 to 98 years [mean \pm standard deviation $(S D)=49.31 \pm 13.95$ years], weight was between 40 to $95 \mathrm{~kg}$ [mean $\pm \mathrm{SD}=63.84 \pm 10.99 \mathrm{~kg}$ ], systolic blood pressure (SBP) of 100 to $180 \mathrm{mmHg}$ [median(interquartile range or $I Q R$ ) $=140(10) \mathrm{mmHg}$, and diastolic blood pressure (DBP) of 60 to $110 \mathrm{mmHg}$ [median $(I Q R)=90(10) \mathrm{mmHg}$ ]. Among the total participants, $41(20.5 \%)$ of them had never gone to school and majority of patients $72(36.0 \%)$ had received only primary level of education. More than three fourth $177(88.5 \%)$ of the participants were married followed by $15(7.5 .5 \%)$ widows. Similarly, 129 (64.5\%) were employment and 71 (35.5\%) were unemployed. A large part of those interviewed 72 (36.0\%) had hypertension for more than 5 years. Most of the patients in our study had diabetes 47 (23.5\%) followed by visual impairment $17(8.5 \%)$ and heart problem $11(5.5 \%)$ (Table 1$)$.

The median(IQR) knowledge (total score 13), attitude (total score $=5$ ) and practice (total score $=18$ ) scores were $11(4), 3(3)$ and $9(2)$ respectively (Table 2 ).

The statistics shows that none of the patients gave $100 \%$ correct answer in each of the question and only $66(33.0 \%)$ patients knew that antihypertensive medicines may sometimes cause hypotension (Table 3 ). Most patients identified that excessive salt intake (186, 93.0\%), alcohol $(181,90.5)$ and being overweight $(177,88.5 \%)$ are the risk factors of hypertension.

More than $50 \%$ patients gave correct answer to all the attitude questions except one related to $(14,35 \%)$ before intervention (Table 4). However, all of the questions were correctly answered by all the participants after the educational intervention but a $100 \%$ result was still not achieved to the attitude question related to exercise 
$(33,82.5 \%)$.

\begin{tabular}{|c|c|c|}
\hline $\begin{array}{l}\text { Table 1. Baselir } \\
(\mathbf{N}=\mathbf{2 0 0}) \text {. }\end{array}$ & socio-demograp & charac \\
\hline Characteristics & Categories & n (\%) \\
\hline Age (years) & 30 to 98 & $200(100.0)$ \\
\hline $\mathrm{SBP}(\mathrm{mmHg})$ & 100 to 180 & $200(100.0)$ \\
\hline $\mathrm{DBP}(\mathrm{mmHg})$ & 60 to 110 & $200(100.0)$ \\
\hline Weight $(\mathrm{kg})$ & 40 to 95 & $200(100.0)$ \\
\hline & Male & $120(60.0)$ \\
\hline sex & Female & $80(40.0)$ \\
\hline & Never married & $5(2.5)$ \\
\hline & Married & 177 (88.5) \\
\hline Marital Status & Divorced & $2(1.0)$ \\
\hline & Separated & $1(0.5)$ \\
\hline & Widowed & $15(7.5)$ \\
\hline & Never went & 41 (20.5) \\
\hline & Primary school & 72 (36.0) \\
\hline & Secondary school & $31(15.5)$ \\
\hline Education & $\begin{array}{l}\text { Post secondary } \\
\text { school }\end{array}$ & $10(5.0)$ \\
\hline & University & $46(23.0)$ \\
\hline & $\begin{array}{l}\text { Government } \\
\text { employee }\end{array}$ & $15(7.5)$ \\
\hline Occunation & $\begin{array}{l}\text { Non-government } \\
\text { employee }\end{array}$ & $25(12.5)$ \\
\hline Uccupation & Self-employed & $70(35.0)$ \\
\hline & Student & $1(0.5)$ \\
\hline & Unemployed & $71(35.5)$ \\
\hline & Other & $18(9.0)$ \\
\hline & $<1$ year & $28(14.0)$ \\
\hline Duration of & 1-2 year & $30(15.0)$ \\
\hline hypertension & $3-4$ years & 49 (24.5) \\
\hline & $\geq 5$ years & $93(46.5)$ \\
\hline Heart Problem & Yes & $11(5.5)$ \\
\hline $\begin{array}{l}\text { Paralysis of } \\
\text { limb }\end{array}$ & Yes & $6(3.0)$ \\
\hline $\begin{array}{l}\text { Visual } \\
\text { impairment }\end{array}$ & Yes & $17(8.5)$ \\
\hline Kidney Problem & Yes & $8(4.0)$ \\
\hline Diabetes & Yes & $47(23.5)$ \\
\hline & 1 & 148 (74.0) \\
\hline Tumber of & 2 & $45(22.5)$ \\
\hline & 3 & $7(3.5)$ \\
\hline Smoker & Yes & $58(29.0)$ \\
\hline & None & $131(65.5)$ \\
\hline & $>$ once per day & $10(5.0)$ \\
\hline & Once per day & $14(7.0)$ \\
\hline Alcohol intake & $\begin{array}{l}\text { Few times per } \\
\text { week }\end{array}$ & $14(7.0)$ \\
\hline & Once a week & $6(3.0)$ \\
\hline & $<$ once a week & $14(7.0)$ \\
\hline & Seldom & $11(5.5)$ \\
\hline
\end{tabular}

\begin{tabular}{|lccc|}
\hline $\begin{array}{l}\text { Table 2. Knowledge, } \\
\text { (N=200). }\end{array}$ & & & \\
\hline Variables & Median(IQR) & Minimum & Maximum \\
Knowledge & score & score & score \\
Attitude & $11(4)$ & 1 & 13 \\
Practice & $3(3)$ & 0 & 5 \\
\hline
\end{tabular}

Table 3. Correct response of the patients towards knowledge $(N=200)$.

\begin{tabular}{|c|c|}
\hline Questions & n (\%) \\
\hline Do you know the normal BP reading? & $154(77.0)$ \\
\hline Do you know what the high BP is? & $140(70.0)$ \\
\hline $\begin{array}{l}\text { Do you know what complications can } \\
\text { arise if BP is not controlled? }\end{array}$ & $124(62.0)$ \\
\hline Is high BP hereditable? & $113(56.5)$ \\
\hline $\begin{array}{l}\text { Is excessive salt intake one of the risk } \\
\text { factors for developing high BP? }\end{array}$ & $186(93.0)$ \\
\hline $\begin{array}{l}\text { Is excessive alcohol intake one of the } \\
\text { risk factors for developing high BP? }\end{array}$ & $181(90.5)$ \\
\hline $\begin{array}{l}\text { Is being overweight one of the risk } \\
\text { factors for developing high BP? }\end{array}$ & $177(88.5)$ \\
\hline $\begin{array}{l}\text { Do you know about the symptoms of } \\
\text { high BP? }\end{array}$ & $182(91.0)$ \\
\hline $\begin{array}{l}\text { Do you know about the symptoms of } \\
\text { low BP? }\end{array}$ & $165(82.5)$ \\
\hline Do you know how high BP is managed? & $164(82.0)$ \\
\hline $\begin{array}{l}\text { Do you have to take antihypertensive } \\
\text { medicines for life long? }\end{array}$ & $191(95.5)$ \\
\hline $\begin{array}{l}\text { Do antihypertensive medicines } \\
\text { sometimes lower you BP below normal? }\end{array}$ & $66(33.0)$ \\
\hline $\begin{array}{l}\text { Is regular BP measurement necessary } \\
\text { for high BP patients? }\end{array}$ & $111(55.5)$ \\
\hline
\end{tabular}

Table 4. Correct response of the patients towards attitude $(\mathrm{N}=\mathbf{2 0 0})$.

Questions $n(\%)$

Should we reduce salt intake to prevent hypertension?

$190(95.0)$

Do you think regular checking of BP is important?

Should we keep in touch with the physician regularly?

Do you think regular medication is important in hypertension?

$107(53.5)$

Should we exercise regularly for healthy life?

$83(41.5)$

Most patients frequently-measured their BP (170, $85.0 \%$ ) and consulted their healthcare providers (134, $67.0 \%$ ); occasionally-moderated their salt intake (129, 
$64.5 \%)$, avoided fatty foods $(160,80.0 \%)$, measured body weight $(156,78.0 \%)$; and never consumed alcohol (118, 59.0\%), performed physical exercise
(103, 51.5\%), never smoked $(134,67.0 \%)$, never missed their medication $(92,46.0 \%$ (Table 5$))$. There were also higher number individuals who occasionally miss their medication $(84,42.0 \%)$.

\begin{tabular}{|c|c|c|c|}
\hline Questions & Frequent n (\%) & Occasional n (\%) & $\begin{array}{l}\text { Never } \\
\text { n (\%) }\end{array}$ \\
\hline How often do you measure your BP? & $170(85.0)$ & $29(14.5)$ & $1(0.5)$ \\
\hline How often do you moderate your salt intake? & $65(32.5)$ & $129(64.5)$ & $6(3.0)$ \\
\hline How often do you avoid fatty food consumption? & $29(14.5)$ & $160(80.0)$ & $11(5.5)$ \\
\hline How often do you consume alcohol? & $27(13.5)$ & $55(27.5)$ & $118(59.0)$ \\
\hline How often do you perform physical exercise? & $22(11.0)$ & $75(37.5)$ & $103(51.5)$ \\
\hline How often do you check your body weight? & $19(9.5)$ & $156(78.0)$ & $25(12.5)$ \\
\hline How often do you smoke? & $24(12.0)$ & $42(21.0)$ & $134(67.0)$ \\
\hline How often do you miss the dose of your medication? & $24(12.0)$ & $84(42.0)$ & $92(46.0)$ \\
\hline How often do you consult your healthcare provider? & $134(67.0)$ & $50(25.0)$ & $16(8.0)$ \\
\hline
\end{tabular}

\begin{tabular}{|c|c|c|c|c|c|c|c|}
\hline \multirow{2}{*}{\multicolumn{2}{|c|}{$\begin{array}{l}\text { Variables } \\
\text { Score }\end{array}$}} & \multicolumn{2}{|c|}{ Knowledge } & \multicolumn{2}{|c|}{ Attitude } & \multicolumn{2}{|c|}{ Practice } \\
\hline & & P-value & Score & P-value & Score & P-value & \\
\hline \multirow{2}{*}{$\operatorname{Sex}^{\ddagger}$} & Male & $11(3)$ & \multirow{2}{*}{$<0.001^{\dagger}$} & $4(2)$ & \multirow{2}{*}{$<0.001 \dagger$} & $9(2)$ & \multirow{2}{*}{0.114} \\
\hline & Female & $9(3)$ & & $3(2)$ & & $8(3)$ & \\
\hline \multirow{5}{*}{$\begin{array}{c}\text { Level of } \\
\text { education }\end{array}$} & Never went & $9(4)$ & \multirow{5}{*}{$<0.001^{\dagger}$} & $3(3)$ & \multirow{5}{*}{$0.016 *$} & $8(3)$ & \multirow{5}{*}{0.367} \\
\hline & Primary & $9.5(4)$ & & $3(2)$ & & $8.5(3)$ & \\
\hline & Secondary & $11(3)$ & & $3(2)$ & & $9(3)$ & \\
\hline & Postsecondary & $11(3)$ & & $4(3)$ & & $9.5(5)$ & \\
\hline & University & $12(2)$ & & $4(2)$ & & $9(3)$ & \\
\hline \multirow{4}{*}{$\begin{array}{c}\text { Duration of } \\
\text { hypertension }\end{array}$} & $<1$ year & $11(3)$ & \multirow{4}{*}{0.673} & $4(3)$ & \multirow{4}{*}{0.185} & $10.5(5)$ & \multirow{4}{*}{$0.001 *$} \\
\hline & $1-2$ years & $10(5)$ & & $3.5(2)$ & & $8(3)$ & \\
\hline & $3-4$ years & $10(4)$ & & $4(2)$ & & $8(3)$ & \\
\hline & $\geq 5$ years & $11(3)$ & & $3(2)$ & & $9(3)$ & \\
\hline
\end{tabular}

${ }^{*} p<0.05,{ }^{t} p<0.001,{ }^{\ddagger}$ Mann-Whitney $U$ test

There was statistically significant association of knowledge and attitude with both sex $(p<0.001$ and $p<0.001$ respectively) and level of education $(p<0.001$ and $p=0.016$ respectively) as depicted in table 6. Higher median scores of knowledge (K) and attitude $(A)$ were seen in male $(K=11$ and $A=4)$ and those with university level education $(K=12$ and $A=4)$.

\section{DISCUSSION}

The current status of knowledge, attitude and practice of hypertension among the hypertensive patients taking antihypertensive medication in the community of Bharatpur (Central Nepal) was explored. Our study showed that the overall KAP scores was found to be medium except knowledge seems to be at a better position than the other two scores. The knowledge and practice of our study population contradicts with the study population of Western Nepal. ${ }^{8}$ However, they had not assessed the attitude. A cross-sectional study in South India, a neighbouring country of Nepal, showed poor attitude scores than our study population. Bharatpur is growing as a medical city and it consists of citizens migrating from various parts of Nepal. The variation in the findings among different studies might be due to variation in education levels, influence of education and awareness available to them.

Majority of the participants in our study had a better understanding and attitude towards the risk of 
excessive salt intake to prevent hypertension. Salt reduction has been suggested as a possible adjunct to pharmacologic treatment to enhance blood pressure control. Several studies have investigated this issue and found that, for hypertensive patients who are receiving antihypertensive medication; salt restriction provides additional benefits in terms of blood pressure control. ${ }^{16}$ However, the practice of salt moderation of our study population was not very impressive. This shows that patients know that they have to moderate their salt intake but they may not have adequate knowledge on total daily intake, dietary plan or even management aspect of their salt intake. This also applies to other dietary habits such as fatty food consumption and alcohol intake. Our study had similar result with that of Western Nepal, except that the patient in our study group had poorer alcohol moderation practice. ${ }^{8}$ There were nearly one fourth patients who were smokers and the same number were also alcohol drinkers which is slightly higher than that depicted by the STEPS survey 2013 by NHRC. $^{4}$ Smoking is a strong risk factor for cardiovascular diseases including hypertension ${ }^{17,18}$ and alcohol intake is strongly associated with smoking. ${ }^{19}$ However, independently moderation of alcohol (10$20 \mathrm{~g}$ for men and up to $10 \mathrm{~g}$ for women) has been cardiovascular protective but consumption beyond these levels in hypertension is risky. ${ }^{20}$ It is also true that an increased prevalence of hypertension in groups with high alcohol consumption has been recognized for a number of years. Majority of studies have reported small but significant elevations in blood pressure in those consuming three or more drinks per day in comparison with non-drinkers. In multivariate analyses the association was shown to be independent of a variety of potential confounding factors, including age, relative body weight, exercise, and smoking status, that are known to be or are likely to be related to both blood pressure and alcohol consumption. ${ }^{21} \mathrm{~A}$ detailed history of alcohol consumption should be obtained from patients with hypertension. Such patients should be encouraged to reduce their consumption and be referred for treatment of alcohol dependence.

Our study found that the attitude and practice of the hypertensive patients in the community of Bharatpur with regard to the medication adherence was at inferior position. Medication non-adherence has been found to be higher in males ${ }^{22}$ due to side effect of impotence caused by some antihypertensive medication that includes thiazides, beta-blockers and alpha-blockers. ${ }^{23}$ But our study population had $20 \%$ higher number of males than females which might have contributed to the number of individuals missing the dose of medication occasionally or frequently. Polypharmacy can have an impact on the medication non-compliance and hence contribute to hypertension prevalence. However, ma- jority of our study population were prescribed single medication and about one fourth were prescribed two medications. Medication adherence in ambulatory patients can be improved by decreasing the frequency of dosing and prescribing at the same time ${ }^{24}$ without altering the efficacy.

The attitude and practice of exercise was found poor in our study. Most patients occasionally checked their body and there were also individuals who never checked their body weight. There is consistent evidence that regular dynamic physical exercise (including walking, cycling, non-competitive swimming and other equivalent leisure activities) decreases both systolic and diastolic blood pressure by $5-7 \mathrm{mmHg}$ independent of weight loss, alcohol intake or salt intake. There is also evidence that moderate intensity exercise, in sessions of 50-60 minutes, 3 or 4 times per week, may be more effective than vigorous exercise in decreasing blood pressure in hypertensive patients. Physical activity has often been used in conjunction with weight reduction strategies for the treatment of hypertension. Increased physical activity, together with a reduction in caloric intake alone or in combination with a reduction in alcohol intake and with or without a reduction in sodium intake reduces the relative risk of hypertension. ${ }^{25}$

We observed a high statistically significant $(p<0.001)$ differences in the knowledge and attitude scores between male and female. A cross sectional study in Pakistan had shown that men had better knowledge than female at $p=0.03 .^{9}$ The reasons of better scores in men might be due to limited opportunities available to women in a society with deep rooted gender bias against female. ${ }^{26}$ However, a KAP study on hypertension by Sharma et al. (2014) suggest that gender is not associated with awareness and practice of patients. ${ }^{8}$ But the KAP score differences among male and female from our study depicts that female are in higher need for educational intervention to improve their current KAP on hypertension in our community. Similarly, a statistically significant difference was also observed in the level of education and KA scores and those with higher education scored better KAP values than those with lesser education level. A similar community based study in Western Nepal also showed influence of education on knowledge and practice score $(p=0.01)$ indicating that literate patients score better than their illiterate counterparts. ${ }^{8}$ A statistically significant association was also observed with the duration of hypertension and practice score which was not observed in the study of Western Nepal. ${ }^{8}$ Interestingly, in our study a decline in the practice score was observed after one year of hypertension. This suggest an intervention at early stage of hypertension might be beneficial than the latter stages. 
The accuracy of the KAP scores may vary with the reluctance of study population to avoid negative impression. Though Bharatpur consist of people migrating from various geographical places and of various ethnicity, we did not consider this while taking the sample.

\section{CONCLUSIONS}

The prevalence of hypertension has an increasing trend globally. Often problem of poor medication of antihypertensive patient is due to the poor knowledge, attitude and practice of patient regarding their treatment and disease. The status of overall KAP on hypertension among antihypertensive users of
Bharatpur need improvement to reduce the burden. A proper educational intervention is essential on the aspect of dietary habits that would rather improve their practice. Our study also highlights the necessity to focus such intervention related to knowledge and attitude on women, and practice oriented intervention to all the patient groups. Patients with earlier onset of hypertension might respond to the intervention better.

\section{ACKNOWLEDGEMENTS}

We would like to thank all the participants who took part in this research. A sincere thanks to Mrs. Prabha Pokharel for measuring the blood pressure of the patients.

\section{Conflict of Interest: None.}

\section{REFERENCES}

1. World Health Organisation. Global Health Observatory (GHO) data: Raised blood pressure [Internet]. [Geneva]: World health Organisation [cited 2015 February 10]. Available from: http://www.who.int/gho/ncd/risk_ factors/blood_pressure_prevalence_text/en/.

2. World Health Organisation. A global brief on hypertension: silent killer, global public health crisis: WHO press; 2013. Section 1, Why hypertension is a major public health issue; p. 9.

3. Lim SS, Vos T, Flaxman AD, Danaei G, et al. A comparative risk assessment of burden of disease and injury attributable to 67 risk factors and risk factor clusters in 21 regions, 1990-2010 : a systematic analysis for the Global Burden of Disease Study 2010. Lancet. 2012; 380 (9859): 2224-60.

4. Nepal Health Research Council. Non communicable disease risk factors: STEPS Survey Nepal 2013: Nepal Health Research Council. [cited 2015 February 15]. Available from: http://nhrc.org.np/files/download/99b7be39021d4ce.

5. Sacks FM, Svetkey LP. Effects on blood pressure of reduced dietary sodium and the dietary approaches to stop hypertension. New Eng J Med. 2002; 344(1): 3-10.

6. Whelton SP. Chin A, Xin X, He J. Effects of aerobic exercise on blood pressure: a meta analysis of randomized controlled trials. Ann Intern Med. 2002; 136(7): 493-503.

7. Xinx X, He J, Fromtini MG, Ogden LG, Motsamai OI, Whelton PK. Effects of alcohol reduction on blood pressure: a meta analysis of randomized controlled trials. Hypertension. 2001; 38(5): 1112-17.

8. Sharma S, KC B, Alrasheedy AA, Kaundinnyayana A, Khanal A. Impact of community pharmacy-based educational intervention on patients with hypertension in Western Nepal. AMJ. 2014; 7(7): 304-13.

9. Almas A, Godil SS, Lalani S, Samani ZA, Khan AH. Good knowledge about hypertension is linked to better control of hypertension; a multicentre cross sectional study in Karachi, Pakistan. BMC Research Notes. 2012; 5: 579-86.
10. Bilal M, Haseeb A, Lashkerwala SS, Zahid I, Siddiq K, Saad M. Knowledge, Awareness and Self-Care Practices of Hypertension among Cardiac Hypertensive Patients. Global Journal of Health Science. 2016; 8(2): 9-19.

11. Oliveria SA, Chen RS, McCarthy BD, Davis CC, Hill MN Hypertension knowledge, awareness, and attitudes in a hypertensive population. J Gen Intern Med. 2005; 20: 219-25.

12. Oli N, Vaidya A, Subedi M, Krettek A. Experiences and perceptions about cause andprevention of cardiovascular disease among people with cardiometabolic conditions: findings of in-depth interviews from a peri-urban Nepalese community. Global Health Action. 2014; 7(24023): 1-11.

13. Bharatpur Sub-metropolitan city: Profile: Bharatpur Sub-metropolitan city [cited 2015 February 15]. Available from: http://bharatpurmun.gov.np/sites/bharatpurmun. gov.np/files/documents/profile.pdf

14. Sharma S, Khanal A, Poudel B, Sharma R, Srivastav S. Knowledge, attitude and outcomes: an effect of pharmacist provided counseling in hypertensive patients in a tertiary care teaching hospital in Western Nepal. Int J Ph Sci. 2010; 2(2): 583-87.

15. Bollu M, Nalluri KK, Surya-Prakash A, Naga-Lohith M, Venkataramarao N. Study of knowledge, attitude and practice of general population of Guntur toward silent killer diseases: hypertension and diabetes. AsianJ Pharm Clin Res. 2015; 8(4): 74-78.

16. Dennison C, Peer N, Lombard C. Cardiovascular risk and comorbid conditions among black South Africans with hypertension in public and private primary care settings: The HiHi study. Ethn Dis. 2007; 17: 477-83.

17. Primatesta P, Falaschetti E, Gupta S, Marmot MG, Poulter NR. Association between smoking and blood pressure: evidence from the health survey for England. Hypertension. 2001; 37: 187-93. 
18. Virdis A, Giannarelli C, Neves MF, Taddei S, Ghiadoni L. Cigarette smoking and hypertension. Curr Pharm Des. 2010; 16(23): 2518-25.

19. Reed MB, Wang R, Shillington Am, Clapp JD, Lange JE. The relationship between alcohol use and cigarette smoking in a sample of undergraduate college students. Addict Behav. 2007; 32(3): 449-64.

20. Puddey IB, Beilin LJ. Alcohol is bad for blood pressure. Clin Exp Pharmacol Physiol. 2006; 33(9): 847-52.

21. Svetkey L. Effects of dietary patterns on blood pressure: subgroup analysis of the Dietary Approaches to Stop Hypertension (DASH) randomized controlled trial. Arch Intern Med. 1999; 159: 285-93.

22. Jin J, Sklar GE, Oh VMS, Li SC. Factors affecting therapeutic compliance: A review from the patient's perspective. Ther Clin Risk Manag. 2008; 4(1): 269-86.)
23. James PA, Oparil S, Carter BL, et al. Evidence-based guideline for the management of high blood pressure in adults. Report from panel members appointed to the Eighth Joint National Committee (JNC 8). JAMA. 2014; 311(5): 507- 20.)

24. Brown MT, Bussell JK. Medication adherence: who care? Mayo Clin Proc. 2011; 86(4): 304-14.

25. Stefanov T, Vekova A, Bonova I, et al. Effects of supervised vs non-supervised combined aerobic and resistance exercise programme on cardiometabolic risk factors. Cent Eur J Public Health. 2013; 21(1): 8-16.

26. Qadir F, Khan MM, Medhin G, Prince M: Male gender preference, female gender disadvantage as risk factors for psychological morbidity in Pakistani women of childbearing age - a life course perspective. BMC Public Health. 2011; 11(1):745-58. 